\title{
A teoria geral dos sistemas na teoria das organizações
}

\author{
Fernando C. Prestes Motta *
}

1. Introdução. 2. Origens. 3. As Grandes Figuras. 4. Idéias Centrais. 5. A Teoria Geral dos Sistemas e a Organizaçao. 6. Criticas.

Estamos presenciando um movimento sui generis no desenvolvimento científico. Parece que, repentinamente, todos os ramos do conhecimento, tornados estranhos uns aos outros pela especialização extremada, começaram a ressentir-se do isolamento em que se encontravam, passando a buscar mais $e$ mais suas bases comuns. Talvez pela necessidade crescente de estudos interdisciplinares, capazes de analisar a realidade de ângulos diversos e complementares, talvez pela comunicação muito mais rápida e fácil entre especialistas em campos diferentes, começou-se a tomar consciência de que uma série de principios desenvolvidos nos diversos ramos do conhecimento cientifico não passavam de mera duplicação de esforços, pois outras ciências já os haviam desenvolvido. Isto não quer dizer, porém, que só haja uma ciência, ou que a física, a química $\theta$ a psicologia tratem dos mesmos objetos. Seria tolice imaginar que todos os principios e conclusões de uma aplicar-se-iam às demais. O que se foi percebendo é que muitos dêsses princípios e conclusões valiam para várias ciências, na medida em que tôdas tratavam com objetos que podiam ser entendidos como sistemas, fôssem êles físicos, químicos, psíquicos etc.

\footnotetext{
- Professor-assistente do Departamento de Administracáo Gerai $\theta$ Relaçóes Industriais da Escola de Administraçăo de Emprésas de Săo Paulo, da Fundaçăo Getüllo Vargas.
}

R. Adm. Emp., Rlo de Janeiro,

\section{Origens}

Com base nessa constatação, alguns cientistas orientaram suas preocupações para o desenvolvimento de uma teoria geral dos sistemas, que desse conta das semelhanças, sem prejuizo das diferenças. Nesse particular, salienta-se a obra do biólogo alemão Ludwig von Bertalanffy que concebeu o modélo do sistema aberto, entendido como complexo de elementos em interação e em intercâmbio contínuo com o ambiente. Em seu livro Teoria geral dos sistemas, êsse autor apresenta a teoria e tece considerações a respeito de suas potencialidades na física, na biologia e nas ciências socigis. No mesmo livro, von Bertalanffy lança os pressupostos $e$ orientações básicos de sua teoria geral dos sistemas, como segue:

a) há uma tendência para a integração nas várias ciências naturais e sociais;

b) tal integração parece orientar-se para uma teoria dos sistemas;

c) essa teoria pode ser um meio importante de objetivar os campos não-físicos do conhecimento científico, especialmente nas ciências sociais;

d) desenvolvendo princípios unificadores que atravessam verticalmente os universos particulares das diversas ciências, essa teoria aproxima-nos do objetivo da unidade da ciência;

11(1): $\quad 17-33$

Jan./Mar. 1971 
e) isso pode levar a uma integraçăo muito necessária na educação científica. ${ }^{1}$

Muitos são os estudiosos que têm procurado aplicar a teoria geral dos sistemas a seus diversos campos. No caso particular das ciências sociais, o modêlo do sistema aberto tem revelado enormes potencialidades, quer pela sua abrangência, quer pela sua flexibilidade. De grande importância são os trabalhos do psicólogo J. G. Miller, do economista Kenneth Boulding, do cientista politico David Easton e do sociólogo Walter Buckley. Embora o impacto da teoria geral dos sistemas venha sendo grande na sociologia, - estágio em que se encontrava a teoria sociológica por ocasião dos primeiros contatos com a nova abordagem fêz com que se iniciasse um processo simbíótico, cujo desenvolvimento é dificil prever. Com efeito, a predominância do funcionalismo de Talcott Parsons na sociologia contemporânea tem possibilitado a essa ciência atingir niveis sempre mais altos de sistematização, apesar das limitaçőes indiscutiveis que tal método apresenta. De qualquer forma, porém, a perspectiva funcionalista também é sistémica, embora bastante diferente daquela da teoria geral dos sistemas.

Para o estudo da aplicação do modêlo do sistema aberto à teoria das organizaçōes, a percepção dêsse processo simbiótico é fundamental, já que se apresenta na maior parte dos trabalhos nessa linha. Fundamental, portanto, parece ser também o conhecimento do funcionalismo. Muito do que dissemos no artigo $O$ Estruturalismo na Teoria das Organizações ${ }^{2}$ vale para o funcionalismo, uma vez que êste não deixa de ser uma forma de estruturalismo. Algumas consideraçőes adicionais, porém, fazem-se necessárias: êste método não nasceu na sociologia, embora tenha atingido, nessa área do co-

\footnotetext{
1 Von Bertalanffy, Ludwig. Ceneral syotem theory. New York, George Brazilier, 1968. p. 38.

2 Prestes Motta, Fernando C. O estruturalismo na téoria das organizaçóes. Reviata de administração de omproseas, E.A.E.S.P., 10 (4): 1970.
}

nhecimento, elevado nivel de divulgação. Essa ciência social recebeu-o da antropologia, e mais especialmente de Radcliffe-Brown e Malinovsky, antropólogos inglêses do período entre guerras que, por sua vez, o importaram da biologia. Na sociologia, foi com Talcott Parsons que o funcionalismo atingiu seu mais alto nível de desenvolvimento. Sociólogos como Spencer e Dürkheim, entretanto, já apresentavam em suas formulações numerosos exemplos de teorização funcionalista, 3 - que demonstra que já existiam na sociologia precondições para a importação do funcionalismo. Foi a obra de Parsons, contudo, que chegou à teoria das organizações, marcando-a profundamente e determinando seu desenvolvimento futuro. Será a ela, portanto, que dedicaremos nossa atenção. O parsonismo, nome pelo qual nos referiremos de agora em diante à obra de Talcott Parsons, está muito longe de ser simples, e qualquer tentativa de tratá-lo em poucas linhas é arriscada senão impossivel. $O$ que procuraremos fazer será simplesmente seguir a evolução do pensamento parsoniano nos seus aspectos básicos, voltando nosso interêsse para a passagem de uma visão micro para a macro, crucial para a consolidação da posição destacada que o parsonismo passou a ocupar como método de análise dos fenómenos sociais.

Alguns estudiosos da teoria sociológica chamam a microabordagem parsoniana de acionismo social $\theta$ sua macroabordagem de imperativismo funcional. $O$ primeiro está voltado para a explicação da ação, enquanto unidade, através de variáveis-padrão; já o segundo para a explicação do sistema social, através de imperativos funcionais. Ambos estão preocupados com o problema da seleção ou estabilização de escolhas, procurando identificar os processos sociais internos e externos que por ela se responsabilizam. Para o acionismo social a resposta está na socialização como processo interno e na di-

3 Ver Berlinck, Manoel T. O funcionaliamo na sociologla e na antropologla. E.A.E.S.P., F.G.V., p. 1. 
ferenciaçāo de papéis e no contróle social como processos externos. Para o imperativismo funcional, está na diferenciaçāo estrutural como processo interno e na especificação normativa e nas transações com o ambiente como processos externos.

As primeiras formulaçð̃es do acionismo social datam dos anos trinta, quando Parsons começou a desenvolver sua teoria da açăo. Por essa época o teórico afirmou que não havia propriedades grupais que não fóssem redutíveis a propriedades de sistemas de ação e que não havia teoria analitica de grupos que não fosse traduzivel em têrmos da teoria da ação. ${ }^{4}$ Nessa ocasião, êle estava especialmente interessado no processo de escolha de meios e fins possiveis para a ação, baseando-se na suposição de que o comportamento humano envolve, necessàriamente, processos volitivos, não importando que 0 ator seja indivíduo, coletividade ou sistema cultural. Para Parsons, na escolha de meios alternativos para o atingimento de um fim, a ação obedece a uma orientaçăo normativa. Assim, dentro da esfera de contrôle do ator, os meios empregados não podem, via de regra, ser concebidos como escolhidos randômicamente ou como completamente dependentes das condições da ação, mas sempre como sujeitos a influência de um "fator seletivo independente determinado", que precisa ser conhecido para a compreensão de um curso de ação concreto. Dessa formulação depreende-se que os têrmos fator seletivo independente determinado ou, simplesmente norma e situaçăo são básicos para a compreensão da análise parsoniana da escolha humana e, portanto, da ação social. Como o conceito de situação é de entendimento relativamente fácil, cumpre conhecer a definição dada por Parsons ao primeiro têrmo. Recorrendo a seu artigo Variáveis-Pa-

4 Parsons, Talcott. The structure of social action. Glencoe, Illinols, Free Press, 1949. p. 747.

5 Parsons, Talcott. Pattern varlables revised - a response to Robert Dubin. American sociological review, 467-83, ago. 1960. drăo Revistas, ${ }^{\bar{D}}$ vemos que o define como uma descrição verbal do curso de ação concreto visto como desejável, combinado com um refôrço no sentido de que certas ações futuras se conformem com ésse curso. Tal definição, porém, não deixa claras as origens da norma. No que se refere a duas normas específicas, a racionalidade econ8́mica e a integraçăo valorativa, entretanto, Parsons afirma que são propriedades emergentes da ação que sòmente podem ser observadas quando uma pluralidade de açóes é tratada como um sistema integrado. Tal afirmação demonstra claramente a gênese social da ação. Essa pressuposição parsoniana torna-se ainda mais clara, quando o autor sustenta que sistemas de valôres-padrão e outros padrões culturais, quando institucionalizados om sistemas sociais e internalizados em sistemas de personalidade, levam o ator à orientação para fins e à regulamentação normativa dos meios e das atividades expressivas, sempre que as necessidades do ator possibilitam escolhas nessas áreas.

De acôrdo com Parsons e Shills, em dada situação, 0 ator confronta-se com uma série de escolhas que precisa fazer antes que a situação faça sentido para êle. O pressuposto é o de que os objetos da situação não interagem com a estrutura

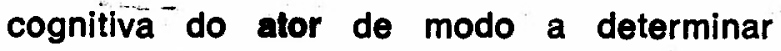
automàticamente o significado da situação. Antes que ela the faça sentido, 0 autor se defronta com cinco dicotomias que orientam sılas escolhas. Tais dicotomias não são nada mais, nada menos, que as variáveis-padrão. Em suma, o que Parsons e Shills sugerem é que qualquer necessidade de personalidade, ou qualquer expectativa de papel da estrutura social envolve uma combinação de valôres das cinco variáveis-padrão. Essas dicotomias permitem trinta e duas combinações diferentes de valơres-padrão básicos. Internalizados no sistema de personalidade, tajs valorres servem de ponto de partida para a classificação dos tipos possiveis de necessida- 
des. Institucionalizados no sistema social, fornecem uma classificação dos componentes das definições de expectativas de papéis. A estabilidade do critério de escolha, por seu turno, fica assegurada pela socialização, pelos mecanismos de diferenciação de papéis e pelos contrôles sociais."

Resumindo, o acionismo social afirma que uma outra alternativa em cada par de variáveis-padrão é engendrada $\theta$ mantida no interior dos que desempenham determinados papéis e que os sistemas de cinco critérios socialmente gerados servem como guia básico do ator para as escolhas das ações requeridas para o desempenho cotidiano. Assim, o papel do médico com relação ao paciente pode ser caracterizado pelo conjunto de universalismo, desempenho, especificidade, neutralidade e orientação coletiva. Por outro lado, o do paciente pode ser caracterizado por um conjunto diverso e complementar. Tais inter-relaçōes de duas ou mais pessoas levam à adoção de uma visão macroscópica, a que se pode chamar imperativismo funcional.

A evolução do pensamento parsoniano do acionismo social para o imperativismo funcional é paralela ao declínio do voluntarismo nesse mesmo pensamento. A medida em que evolui a teoria, os elementos socialmente gerados vão dando lugar aos impostos. Assim, enquanto o acionismo social se concentra no processo de escolha, o imperativismo enfatiza a seleção de alternativas. Seu pressuposto $\dot{a} 0$ de que todo siatema social enfrenta quatro imperativos funcionais aos quais não pode deixar de satisfazer. Tais imperativos são 0 da manutenção, satisfeito pelos valôres sociais $\theta$ subsistemas culturais, 0 da integraçăo, satisfeito pelas normas sociais e subsistemas sociais, 0 do atingimento de metas, satisfeito pelas coletividades sociais e subsistemas políticos e o da adaptabilidade, satisfeito pelos papéis sociais e subsistema econômico. A manutenção se refere à

6 Parsons, Talcott \& Shlils, Edward A. Toward a general theory of action. New. York. Harper Tochbooks, 1951. p. 56. estabilidade do sistema de valores institucionalizados; 0 atingimento de metas refere-se à relação entre 0 ator e um ou mais objetos da situação, relação esta que maximiza a estabilidade do sistema, já que êste precisa atingir metas através do contrôle dos elementos da situação; a adaptabilidade refere-se ao contróle, êle próprio, do ambiente para o atingimento de metas e, finalmente, a integração refere-se à manutenção de solidariedade entre as unidades para o funcionamento eficiente do sistema. ${ }^{7}$

Isto quer dizer que todo e qualquer sistema social deve ser estudado em têrmos de manutenção, atingimento de metas, adaptabilidade e integraçāo, ou melhor, em têrmos dos meios que utiliza para satisfazer êsses imperativos funcionais. Tal afirmação implica na observação de que o funcionalismo é altamente abrangente, pretendendo explicar através de um grande aparato conceitual tôda a enorme variedade de sistemas sociais existentes. No que se refere à análise organizacional, teorizações funcionalistas estão já presentes nas obras de vários estruturalistas como Merton, Gouldner e Etzioni. Além disso, - próprio Parsons escreveu um artigo de especial interêsse para nós, por tratar exclusivamente da organização. Trata-se de Sugestōes para uma Abordagem Sociológica da Teoria das Organizaçōes. ${ }^{8}$

Outras influências também têm sido absorvidas por muitos dos estudiosos que adotaram o modélo do sistema aberto na teoria das organizações. Entre essas são bastante significativas as exercidas pela psicologia social, especialmente pela obra de F.H. Allport. que, libertando-se de uma concepção behaviorista estreita, desenvolveu suas idéias em uma linha bastante adequada à abordagem sistêmica das organizações. Nessa linha, sua definição de estrutura como ciclos de eventos

7 Ver Wallace, Walter L. Sociological theory. Chicago. Aldine Publishing, 1969.

8 Parsons, Talcott. Suggestions for a soclological approach of the theory of organizations. Administrative quarterty. Cornell University, Ithaca, 1 (1 e 2): 1956. 
paralelos ou tangenciais que ocorrem em um sistema social não só amplia o campo da psicologia social, antes limitado acs pequenos grupos, como também procura explicar a in. teração dos elementos de um sistema social.

\section{As grandes figuras}

Vários têm sido os esquemas conceituais propostos por teóricos das organizações que optaram pelo modêlo do sistema aberto. A ordem em que tais esquirmas serão acresentados parece corresponder, a grosso mucio, a nives de complexidade sempre mais altos.

Entre os pioneiros no esfôrço de desenvolver uma análise organizacional sistêmica estāo, indiscutivelmente, os estudiosos . do Instituto de Relações Humanas de Tavistock, na Inglaterra, entre os quais se destacam os nomes E.L. Trist e A.K. Rice. Suas análises partem de pesquisas realizadas nas minas de carvão de seu pais e na indústria têxtil indiana. De especial interêsse são os livros Escolha organizacional, de Trist, e A emprêsa e seu ambiente, de Rice. Outro livro de Rice é Produtividade e organização social: a experiência de Ahmedabad. Devemos a Trist a identificação de dois subsistemas da organização: técnico e social, o primeiro compreendendo as demandas da tarefa, a implantação física e o equipamento existente, sendo portanto responsável pela eficiência potencial da organização e, o segundo, pelas relações sociais daqueles encarregados da execução da tarefa, que transformam a eficiência potencial em eficiência real. Rice preocupa-se mais com as transaçōes da organização com seu ambiente. Para èsse autor, qualquer emprêsa, considerada como um sistema aberto, pode ser definida por suas importaçōes e exportaçōes, isto e, pela manifestação de suas relaçōes com o ambiente. ${ }^{\prime}$

A grande mensagem do modélo de Tavistock parece ser a de que a organização

9 Rice. A. K. The enterprise and the environment. London, Tavistock Publications, 1963. p. 16. eficiente precisa levar em conta tanto as importações que o subsistema social faz do ambiente, isto é, valôres e aspirações, como também as que faz o subsistema técnico, ou seja, matérias-primas, equipamentos etc.

Um esquema conceitual de maior complexidade é proposto pelo sociólogo George Homans em seu livro The human group. Tal esquema, embora aplicável às organizações complexas, pretende aplicar-se principalmente aos pequenos grupos.

Para Homans, 0 ambiente em que existe um sistema social é diferenciado e tal diferenciação define atividades e interaçōes aos participantes do sistema. Ao conjunto dessas atividades $e$ interações impostas pelo ambiente, quer fisico, cultural ou tecnológico, 0 autor chama sistema externo. As variáveis básicas dêsse esquema conceitual são atividades, interações e sentimentos. Tais variáveis são apresentadas como interdependentes, ou seja, qualquer modificação em qualquer delas irá produzir transformações nas demais. Assim, pode-se afirmar que quanto mais elevado fôr o grau de interação de duas ou mais pessoas, mais positivos serão os sentimentos que nutrirão uma (s) para com a (s) outra (s) e vice-versa. Tais sentimentos positivos, por seu turno, produzirăo novas normas, novas atividades $e$ assim por diante. . $O$ autor conclui que, além das atividades e interações impostas pelo ambiente, há atividades $e$ interaçōes geradas pelo próprio sistema. Ao conjunto dessas atividades $e$ interação êle chama sistema interno. Sistema interno e sistema externo, por sua vez, não são apenas dependentes entre si; $a$ interdependência inclui também o ambiente. Referindo-se aos cuidados que deve ter a liderança para ser eficiente, Homans considera a situação total um complexo que inclui os seguintes elementos:

a) ambiente físico e social, incluindo no último os grupos maiores, dos quais os participantes do grupo fazem parte ou com os quais mantêm contatos; 
QUADRO I: O Modelo de Tavistock

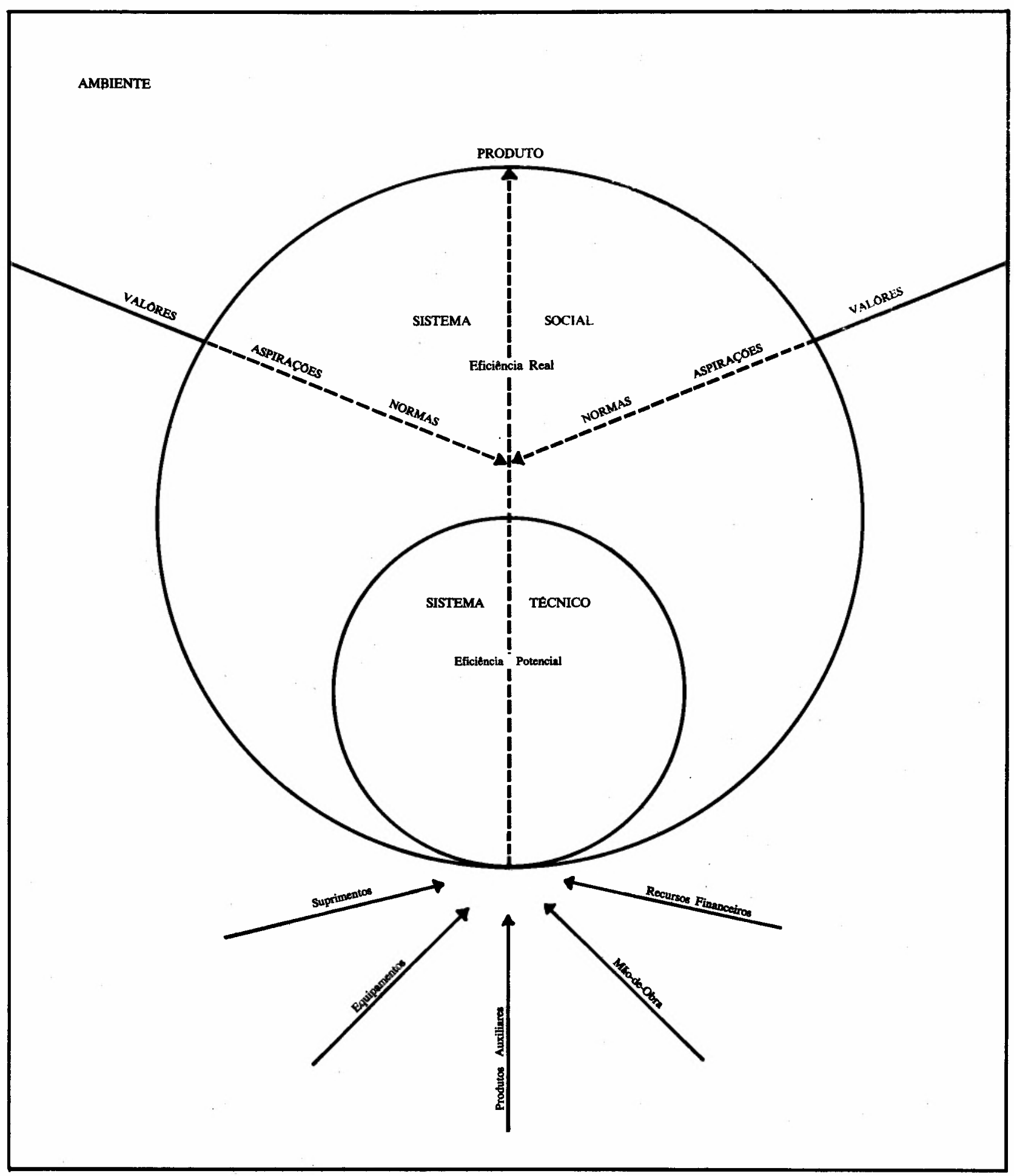


b) os materiais, ferramentas e técnicas com os quais 0 grupo atua sôbre 0 ambiente;

c) o sistema externo, isto 6 , as relaçőes entre os membros do grupo, necessárias a sua ação no ambiente;

d) o sistema interno, isto e, as relaçōes sociais que se desenvolvem a partir do sistema externo e reagem a éle;

e) as normas do grupo.

Lembra ainda que todos esses elementos são interdependentes e que qualquer mudança em um déles acarretará transformaçōes nos demais. ${ }^{10} \mathrm{Um}$ outro livro interessante de Homans é Comportamento social: suas formas elementares. Resta dizer que êsse sociólogo é provàvelmente a segunda grande figura da sociologia americana contemporânea.

Os três esquemas conceituais, que serão apresentados a seguir, foram desenvolvidos pelo grupo de estudiosos do Centro de Pesquisa Social da Universidade de Michigan, nos Estados Unidos, dirigido por Rensis Likert.

O primeiro déles é do próprio Likert, tendo sido apresentado em seu livro Novos padrōes de administraçăo. Esse autor sugere que a organização pode ser vista como um sistema de interligação de grupos. Sugere, ainda, que os grupos são ligados por Individuos em posiçōes-chave, que pertencem ao mesmo tempo a dois ou mais grupos. Da mesma forma, a organização relaciona-se com o seu ambiente através désses indivlduos que desempenham o papel de elos de ligação. Esse amblente, contudo, não é algo impessoal, mas sim um conjunto de outros sistemas. A essa altura, Likert distingue os vários sistemas que compóem o ambiente de uma dada organização. Há, em primeiro lugar, os sistemas de larga escala, tais como - sistema industrial ou a sociedade global; em segundo lugar, os sistemas do mesmo nivel, tais como as organizações concorrentes,

10 Homans, George C. El grupo humano. Eudeba, Editorial Universitaria de Buenos Aires, 1950. p. 449. fornecedoras ou consumidoras; e, finalmente, em terceiro, as subestruturas, tais como grupos formais e informais.. Grande atenção Á dedicada por Likert à coordenação. Segundo êle, o sucesso de uma organização depende do esfórço coordenado de seus membros e tal esfôrço implica na compreensão das características organizacionais básicas, as quais identifica como estrutura, processos de coleta de informaçóes e mensuração, de comunicação e tomada de decisões, recursos para a execução, além de processos de influenciação, conjunto de atitudes e motivaçóes. 11 A principal mensagem do autor, porém, parece ser a de que a organização eficiente deve estar alerta às relaçōes internas e externas, maximizando o desempenho dos elos de ligação, no sentido de seus interésses.

Outro esquema muito interessante é o apresentado por R.L. Kahn, D.M. Wolfe, R.P. Quinn, J.O. Snoeck e R.A. Rosenthal em seu livro Stress organizacional: estudos sôbre conflito de papéis o ambigüidade. Esses autores consideram o esquema de Likert de grande validade, mas sugerem que aquêle autor não ¿istinguiu claramente os grupos psicológicos dos elos de ligação. Para êles, é mais interessante a utilização do conceito de conjunto de papéis (role set) do que de grupo. Assim, não são pessoas, em seritido absoluto, que estão interligadas, mas sim pessoas desempenhando determinados papéis. Existem, portanto, conjuntos de papéis, os quais apresentarão determinadas estruturas. A organização pode, pois, ser pensada em têrmos de um sistema de conjuntos de papéis que se sobrepõem e se ligam, saindo alguns dos limites da própria organização. A partir dessas idéias os autores estudam os conflitos de papéis e a ambigüidade, dando atenção especial à interdependéncia de variáveis tais como posição na organização, aspirações, percepção, reações aos conflitos e eficiéncia. ${ }^{12}$

11 LIkert, Renisis. Now patterns of management. Toqulo, International Student Edition, Kogakusha Company. 1961. p. 178. 
Esse esquema fol integrado em outro mais amplo e complexo por R.L. Kahn $\theta$ D. Katz em seu livro Psicologia social das organizaçóes. Essa obra procura apresentar em um nivel relativamente alto de detalhe a aplicação da teoria geral dos sistemas à teoria das organizações, partindo de uma comparação das potencialidades das principais correntes sociológicas e psicológicas para a análise organizacional. A principal proposta dos autores é no sentido de que a teoria das organizaçōes se liberte do dilema indivíduoestrutura, que as abordagens de base psicológica e sociológica não conseguiram resolver. Para êles a solução daquele dilema está na adoção da teoria geral dos sistemas. Seu esquema conceitual, porém, está, mais do que todos os outros, repleto de influências parsonianas, bem como da psicologia social de F.H. Allport, a quem o iivro é dedicado.

Para Katz e Kahn, a organização não possui estrutura no sentido usual do tôrmo, isto é, de autonomia física identificável e permanente. Sua estrutura só pode ser identificada no sentido definido por F.H. Allport, isto é, como ciclos de eventos. Assim, em têrmos gerais, poderíamos afirmar que a estrutura de uma organização difere em natureza daquela dos sistemas físicos e biológicos, sendo inseparável de seu funcionamento.

Outras obras importantes de Kahn são Poder e conflito nas organizações, co-autoria de Elise Boulding, e Liderança em relaçăo à produtividade e moral, co-autoria de D. Katz. Désse último, é também importante a obra Psicologia social, co-autoria de R.L. Schanck. Além disso, ambos escreveram artigos do maior interêsse, bem como capítulos esparsos de livros na área da teoria das organizações.

Outros esquemas conceituais interessantes são os desenvolvidos por Johnson, Katz e Rosenzweig em seu livro já clássico Teorla e administraçăo de sistemas; por Lawrence e Lorsch (modêlo de diferenciaçăo e

12 Ver Schein, Edgar $H$. Psicologia na Indúatria. LIs. boa, Clássica Editora, 1968. p. 212-22. integração); e por Carzo e Yanouzas em Organizaçőes formais - uma abordagem sistêmica (um esfôrço em direção da quantificação).

\section{Idóias centrais}

\subsection{O Homem Funcional}

De acórdo com a abordagem sistêmica, a organização é vista em têrmos de comportamentos inter-relacionados. Há uma tendência muito grande a enfatizar mais os papéis que as pessoas desempenham do que as próprias pessoas, entendendo-se papel como um conjunto de atividades associadas a um ponto específico do espaço organizacional, a que se pode chamar cargo. Como observamos ao citar o esquema conceitual de Kahn, Wolfe, Quinn, Snoek e Rosenthal, a organização acaba por ser entendida como um sistema de conjuntos de papéis, mediante os quais as pessoas so mantêm inter-relacionadas. No interior de um conjunto de papéis, um indivíduo exerce determinadas açōes para relacionar-se com os demais; tais açōes compõem o comportamento do papel. Além disso, cada participante de um conjunto de papéis mantém determinadas expectativas

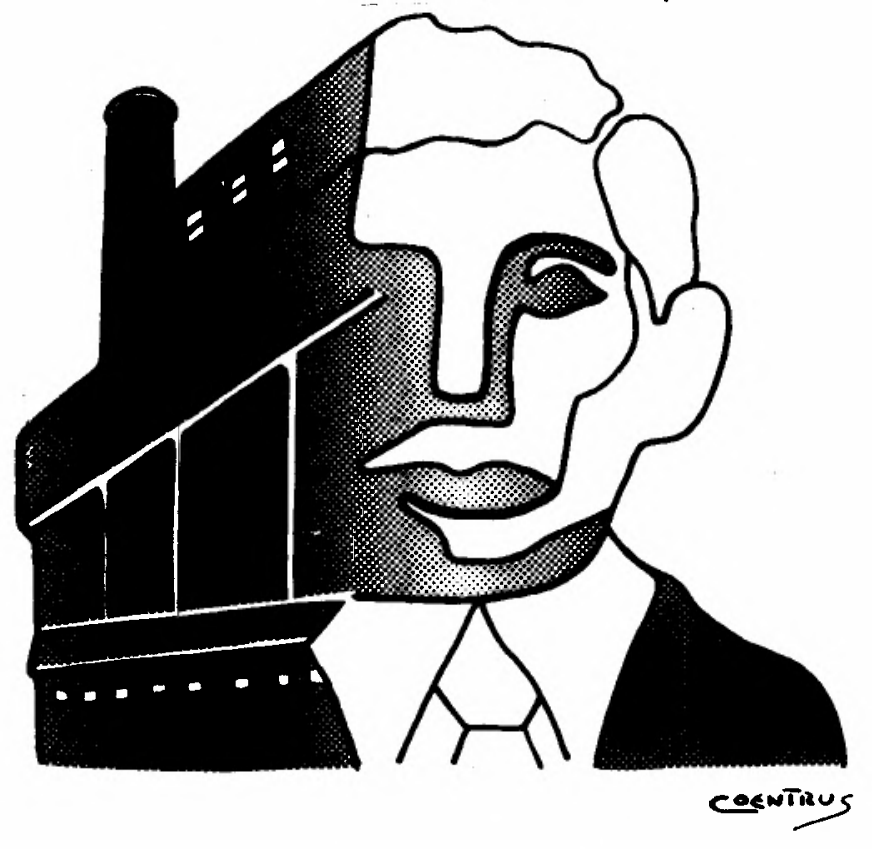

Revista de Administreção de Empressas 
quanto ao papel dos demais e procura enviar aqueles essas expectativas. Da mesma forma, cada participante percebe e interpreta tais expectativas no sentido de alterar ou reforçar o seu comportamento do papel. Por sua vez, êsse comportamento irá alterar ou reforçar as expectativas de papel dos demais.

Esse esquema não é, contudo, fechado. Nêle intervêm variáveis que compõem o contexto em que está inserido. Tais variáveis são de trés classes: organizacionais, de personalidade $e$ interpessoais. Assim, a posição que o individuo ocupa na hierarquia, a maior ou menor flexibilidade de sua personalidade $e$ as relações interpessoais que mantém são de enorme importancia para o processo. Na verdade, podemos concluir que todos os aspectos de comportamento de um indivíduo são relevantes para o desempenho de um papel. Katz e Kahn, em seu livro Psicologia social das organizaçóes, sugerem que um dos grandes entraves à identificação do homem com a organização é sua "inclusão parcial", isto e, a organização não quer o homem integral, mas apenas os aspectos que considera relevantes para a tarefa a ser executada, sendo tais aspectos geralmente definidos de forma muito estreita. Um método comum utilizado pelas organizaçōes para evitar a manifestação de aspectos individuais considerados irrelevantes é a descrição precisa de uma única maneira certa de executar uma tarefa e o contrôle por supervisão cerrada. A ésse respeito, muitas pesquisas realizadas nas duas últimas décadas têm revelado que trabalhadores livres para estabelecer seu próprio ritmo de trabalho tendem a ser mais produtivos. E evidente que liberdade por si só não garante produtividade; tudo depende de como essa liberdade é oferecida. A evidéncia das pesquisas realizadas nessa área é a de que administradores bem sucedidos geralmente estabelecem metas e objetivos amplos, impondo poucas direções especificas. Trabalhos empiricos interessantes nesse sentido são os de Kahn (1958), Katz e Kahn (1951) e Mann e Dent (1954). Suas conclusōes gerais tornam claro o fato de que administradores bem sucedidos, utilizando um padrão realmente democrático de liderança, com muita participação dos subordinados, obtém désses um alto grau de envolvimento e de interésse pelo trabalho, além de maior responsabilidade. Meltzer, em 1956, estudando o comportamento de cientistas, chegou a conclusōes muito semelhantes. 0 sucesso do cientista no desempenho de seu papel parece estar diretamente relacionado com os recursos de que dispóe para seu trabalho e com a liberdade de que desfruta. Importante, porém, é não imaginar que a liberdade está relacionada apenas com 0 trabalho tradicionalmente definido como intelectual ou artístico. Pode ser bem verdadeiro que os especialistas que compóem 0 departamento de criação de uma agéncia de propaganda ou o departamento de pesquisa e desenvolvimento de um laboratório necessitem mais de liberdade do que o pessoal burocrático. Entretanto, se quisermos promover a identificação com a organização, 0 interêsse pelo trabalho e a iniciativa, devemos estender a liberdade a todos, embora sempre levando em conta a natureza das atividades a serem desempenhadas. Além disso, para que a liberdade aja realmente como fator de maior produtividade, duas outras variáveis, porém, devem ser consideradas: a interação o o estímulo. Para que 0 indivíduo livre seja produtivo, deve fazer parte de fato de um sistema social ativo. A interação motiva 0 indivíduo, já que êle passa a conhecer as expectativas que os outros têm de seu papel. O estímulo, por sua vez, lhe dá a medida de como o seu comportamento está atendendo às expectativas e o incita a alterá-lo ou a prosseguir. Likert e Willits (1940) fizeram um estudo que demonstrou muito bem a interdependência dessas variáveis em companhias de seguro. ${ }^{13}$

Se estamos apresentando liberdade e interação como variáveis interdependentes, é

13 Ver Likert, Rensls. New pattems of management. Op. cit., p. 20. 
evidente que entendemos liberdade de uma forma ampla. Existe uma concepção maís estreita de liberdade, incompativel com a interação social. É verdade que, para interagir, os homens são obrigados a fazer concessões. $E$, porém, do processo de interação que retiram suas satisfações, inclusive a noção de liberdade. 0 importante é que $O$ individuo se sinta livre. Como lembra Homans, citando Dürkheim: "Uma sociedade é livre à medida que exige de seus membros um comportamento natural". ${ }^{14}$ Tal afirmação pode ser transportada para o nivel organizacional.

\subsection{Os Conflitos de Papéis}

Quando, a propósito da idéia do homem funcional, discorremos sôbre o sistema de papéis, frisamos que tal sistema é aberto $e$ que $\dot{\theta}$ influenciado por três classes de variáveis: organizacionaís, de personalidade $\theta$ relações interpessoais. Vamos, agora, ver quais as variáveis que compóem cada uma dessas classes.

Em primeiro lugar, as expectativas de papel são em grande medida determinadas pelo contexto organizacional mais amplo. Estrutura organizacional, especialização funcional, divisão de trabalho e o sistema formal de recompensas determinam grandemente 0 que uma pessoa deve fazer. Regra geral, as condiçőes organizacionais que definem a posição de uma pessoa determinam sua experiência organizacional, suas expectativas e as pressões que tal experiência e tais expectativas the impóem.

Em segundo lugar, as propensões pessoais a agir de certo modo, os motivos, valóres, a sensibilidade, as angústias e os hábitos individuais afetam o sistema de papéis de várias formas. Alguns traços de personali-

14 Ver Homans, George. The human group. Op. cit. p. 333.

15. Ver Kahn, R. L., Wolfe, D. M., Quinn, R. P., Snoeck. J. D. \& Rosenthal, R. A. Organizational stress: studies in role conflict and amblgulty. New York, John Wiley and Sons, 1964. p. 33. dade, por exemplo, facilitam a obtenção de resposta dos outros a um dado comportamento; além disso, conforme os seus traços de personalidade, uma pessoa irá perceber pressōes externas, o que implica o fato de que tais pressões são recebidas e afetam diferentemente pessoas distintas.

Em terceiro lugar, a forma como uma pessoa se comporta no sistema de papéis irá afetar o seu futuro comportamento, no sentido de alterá-lo ou reforçá-lo, mas também afetará a sua própria personalidade e as suas relaçōes com os demais. Assim, relações interpessoais passadas e presentes afetarão relações interpessoais futuras. ${ }^{15}$

Em função das variáveis internas e externas intervenientes $a$ natural o surgimento de conflitos, que podem ser genericamente chamàdos conflitos de papéis. Esses conflitos podem ser de vários tipos. Há em primeiro lugar o conflito interno que ocorre quando as expectativas de papel de um participante do conjunto são incompativeis entre si. Há, em segundo lugar, o conflito que ocorre quando as expectativas de dois ou mais participantes do conjunto são incompativeis. Em terceiro lugar, temos o caso das expectativas de um papel serem incompativeis com as expectativas de outro desempenhado pela mesma pessoa $e$, ainda, 0 conflito interno que ocorre quando as expectativas de uma pessoa se chocam com as expectativas do conjunto de papéis em que está inserida. Finalmente, há o caso em que as expectativas não são incompativeis, mas a pessoa não é capaz de satisfazer as expectativas próprias e dos demais no tempo e nos padrões de qualidade exigidos. Kahn e seus colaboradores chamam tais conflitos respectivamente de: intrasender, intersender, interrole, conflito pessoal de papel e sobrecarga do papel.

Segundo os mesmos autores, as origens $\theta$ as conseqüências dos conflitos de papéis podem ser resumidas na afirmação de que expectativas contraditórias de papéis provocam pressóes opostas de papéis, que ge- 
ralmente afetam a experiencia emocional de uma pessoa, intensificando os conflitos internos, aumentando a tensão associada com vários aspectos do trabalho, reduzindo a satisfação com o trabalho e dominando a confiança nos superiores e na organização como um todo. O conflito de papéis tem um custo muito grande para o indivíduo em têrmos emocionais e interpessoais e também representa um alto custo para a organização, na medida que esta depende da coordenação e colaboração efetiva interna e externa de suas partes. ${ }^{16}$

\subsection{Incentivos mistos}

Uma pesquisa realizada pelo Centro de Pesquisa Social da Universidade de Michigan, em 1951, revelou aspectos muito importantes do problema dos incentivos. Essa pesquisa foi levada a cabo em uma grande empressa industrial, que havia adotado padrões de tempo para uma parcela substan- cial de seus cargos. O pagamento, todavia, não era por peça, mas por dia de trabalho. Aos operários foi feita a seguinte pergunta: "Pessoas diferentes desejam coisas diferentes. Quais as coisas que voce considera importantes no trabalho?" Os dados do quadro 3 mostram a freqüencia de escolhas feitas pelos operários quando thes foi pedido que colocassem as trés coisas que consideravam mais importante em uma lista de dez itens. Aos supervisores foi solicitado que indicassem quais as coisas que, na sua opinão, os trabalhadores indicariam $\theta$ quais as que éles próprios consideravam mais importantes. Aos supervisores gerais (um nivel mais alto) foi feito pedido idéntico. A lista de dez itens inclula tanto variáveis económicas quanto variáveis psicossociais, distribuidas aleatóriamente quando apresentadas aos pesquisados. Como se pode observar pela leitura do quadro 3, os superiores superestimaram bastan-

16 Idem. p. 70.

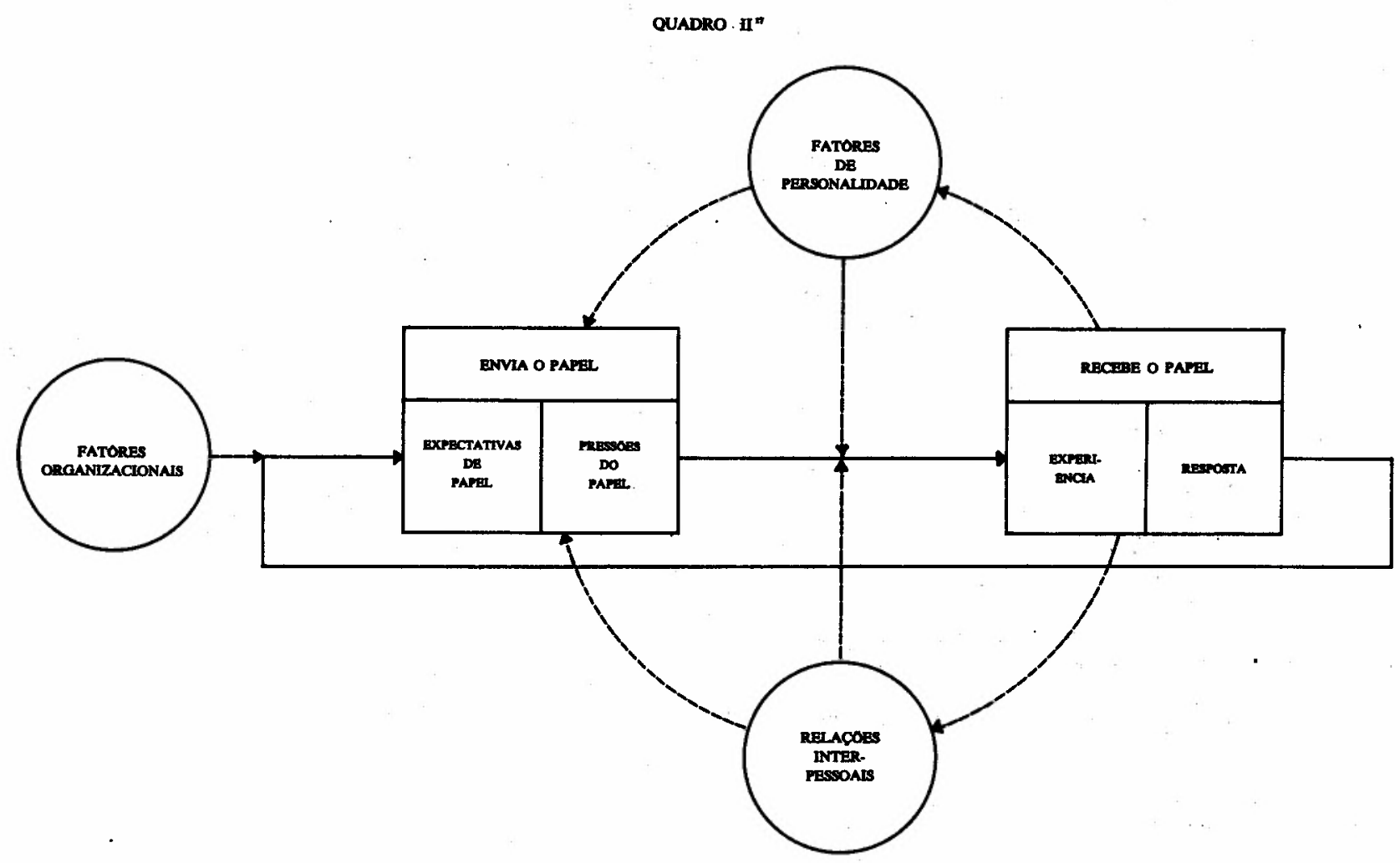


te a importancia que os subordinados davam aos fatóres económicos e subestimaram a que davam aos fatores psicossociais. Assim, no que diz respeito a altos salários, $61 \%$ dos supervisores estimaram que seus subordinados thes dariam grande importancia, todavia apenas $28 \%$ consideraram dessa forma.

Likert sugere, porém, que por várias razões ésses dados năo dâo uma idéia clara da importancia, indiscutivelmente grande, dos motivos económicos na situaçăo de trabalho. Embora não entre na análise dessas razōes, - fato de a pesquisa ter sido realizada pelo Instituto de Pesquisa Social da Universidade de Michingan, o qual ele dirige, dá-lhe credibilidade suficiente. A principal generalização a que chega Rensis Likert a partir dessa - de outras pesquisas relativas a motivação é a seguinte:

"Os supervisores e administradores na indústria $\theta$ no govérno norte-americano que tém conseguido altos índices de produtividade, custos baixos, menor índice de rotatividade de pessoal e absenteísmo, aiém de altos niveis de motivação e satisfação de seus subordinados, adotam, em geral, um padrão de liderança diferente daquele adotado pelos que atingem niveis mais baixos. Tal padrão de liderança difere muito do pregado pelas teorias tradicionais da administração". ${ }^{18}$ Parece que só uma visão sistémica da organizaçăo pode indicar as linhas mestras desse padrăo. A partir dessa generalização, Likert caminha para o desenvolvimento de seu modelo, de grande importancia para a perspectiva sistêmica das organizaçס̄es, como um passo decisivo em direçăo do modelo de Katz e Kahn, que será a seguir objeto principal de nossa atenção.

17 Kahn, R. L., Woife, D. M., Quinn, R. P., Snoeck, J.D. \& Rosenthal, R.A. Organizational strese: studies in role conniet and amblgulty. Op. cit. p. 30.

18 Llkert, Rensis. Now patterns of management. Op. cit. p. 47.

19 Ver Katz, David \& Kahn, A. L. The social poychology of organizations. New York, John Wiley and Sons, 1966.

\section{A teoria geral dos sistemas e a organiza-} ç̆o.

Quando discorremos sobbre as grandes figuras da perspectiva sistémica na teoria das organizaçōes, procuramos dar ao leitor uma rápida idéia dos modelos que propuseram. Neste item do artigo, pretendemos detalhar mais o esquema conceitual de Katz e Kahn que nos parece 0 mais abrangente ie complexo. ${ }^{19}$

O pressuposto básico désse esquema ou modélo $\dot{\theta}$, evidentemente, 0 de que a organização é um sistema aperto. Como tal, ela apresenta as seguintes características:

a) Importação de energia

A organização recebe insumos do ambiente, ou seja: matéria-prima, mão-de-obra etc.

b) Processamento

A organização processa êsses insumos com vistas a transformá-los em produtos, entendendo-se como tai: produtos acabados, mão-de-obra treinada etc.

c) Exportação de energia

A organização coloca seus produtos no ambiente.

\section{d) Ciclos de eventos}

A energia colocada no ambiente retorna à organização para a repetição de seus ciclos de eventos. Sáo eventos, mais do que coisas, que são estruturados, de modo que estrutura venha a ser um conceito mais dinâmico que estático. Dessa forma, o método básico para identificar uma estrutura organizacional é seguir a cadeia de eventos desde a importação até o retôrno da energia.

e) Entropia negativa

Entropia é um processo pelo qual todas as formas organizadas tendem a homogenização e, finalmente, à morte. A organização, porém, através da reposição qualitativa de energia pode resistir ao processo entrópico. A êsse processo reativo chamamos entropia negativa. 


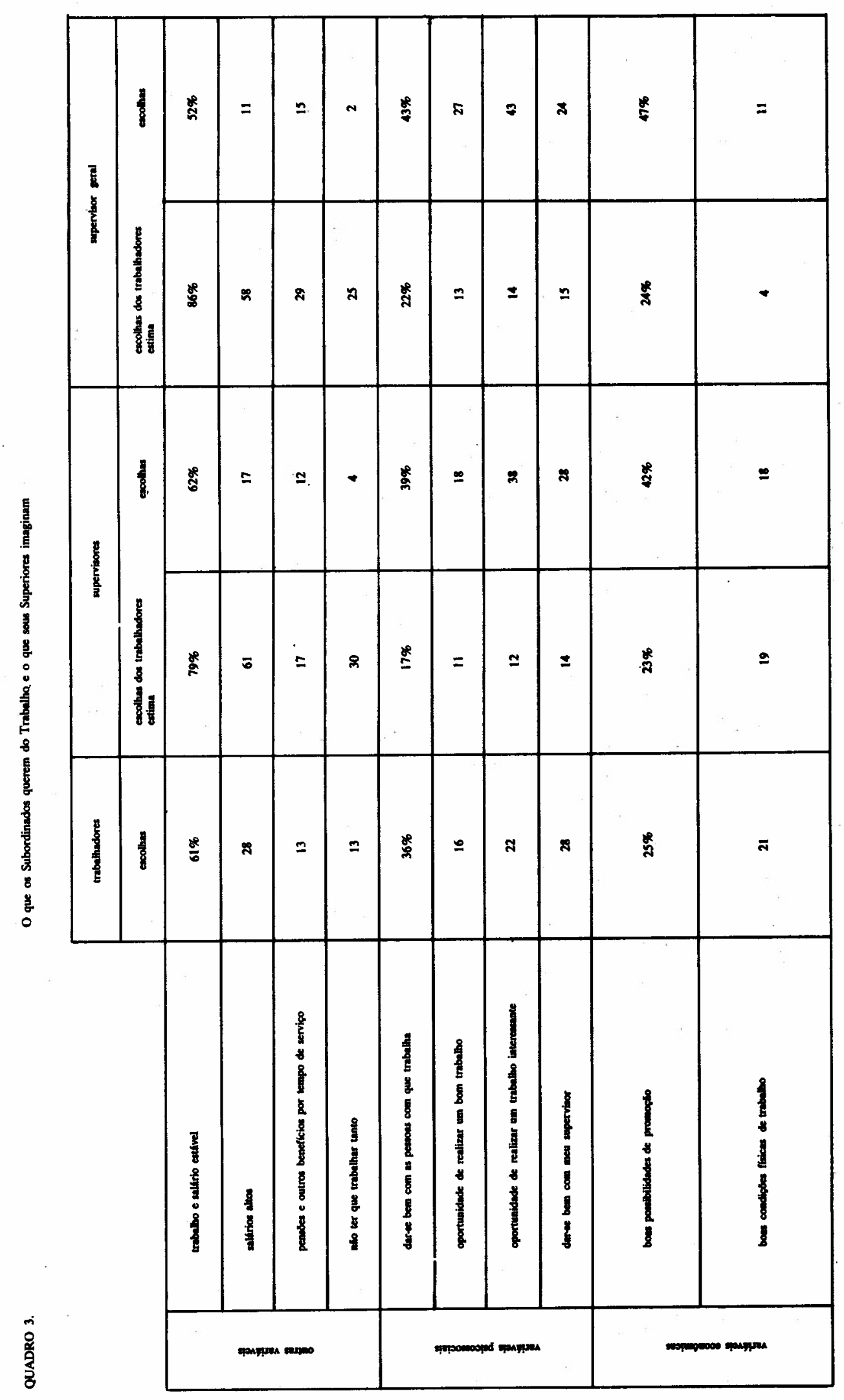


f) Informaçăo como insumo, contrôle por retroalimentação e processo de codificação

Os insumos recebidos pela organização podem ser também informativos, possibilitando a esta o conhecimento do ambiente $\theta$ do seu próprio funcionamento em relação a éle. O processo de codificação permite à organizaçăe receber apenas as informações para as quais está adaptada e o contróle por retroalimentação, a correção dos desvios.

g) Estado estável e homeostase dinâmica

Para impedir o processo entrópico, a organização procura manter uma relação constante entre exportação e importaçăo de energia, mantendo dessa forma o seu caráter organizacional. Entretanto, na tentativa de se adaptar, a organização procura absorver novas funçôs, ou mesmo subsistemas. Tal processo de expansão faz com que ela assuma seqüencialmente estados estáveis de níveis diferentes.

h) Diferenciaçăo

Em função da entropia negativa, a organização tende à multiplicação e à elaboração de funçōes, o que determina também multiplicação de papéis $\theta$ diferenciação interna. i) Eqüifinalidade

Não existe uma única maneira certa de a organização atingir um estado estável. Tal estado pode ser atingido a partir de condições iniciais $\theta$ através de meios diferentes.

Como sistema aberto, a organização apresenta ainda limites, isto é: barreiras entre o sistema 0 o ambiente, que definem sua esfera de ação, $\theta$ um determinado grau de abertura, que dá uma idéia da sua receptividade a Insumos.

Ocorre ainda que organizaçōes são uma classe de sistemas sociais, que por sua vez constituem uma classe de sistemas abertos. Como sistema social ela apresenta um subsistema de produçåo, relacionado com a transformaçăo de insumos em produtos, cujos ciclos de atividades compóem suas principais funçб̄es; subsistemas de suportes, que procuram $\theta$ colocam energia no ambiente $\theta$ tratam da manutenção de bom relacionamen- to com outras estruturas dessse ambiente; subsistemas de manutençăo, que se responsabilizam pela realização do processamento, isto é, que tratam da ligação das pessoas ao sistema, através de recompensas e punições; subsistemas adaptativos, que sentem mudanças ambientais relevantes e traduzem-nas para a organização $\theta$, finalmente, subsistemas administrativos, que são compostos por atividades organizadas para o contrôle, a coordenação $\theta$ a direção dos vários subsistemas. Os dois principais subsistemas administrativos são as estruturas reguladoras (legislativas) e as de tomada de decisões.

A organização se distingue, porém, dos demais sistemas sociais pelo seu alto nivel de planejamento. Em função disso, ela utiliza também um alto nivel de contrôle, que inclui pressões ambientais e valôres e expectativas compartilhadas, mas especialmente a aplicação de regras, cuja violação implica em penalidades. Um dos pontos importantes da perspectiva sistẹmica da organização é a boa compreensāo dos conceitos de papéis, normas $\theta$ valôres, principais componentes de um sistema social. Quanto a papéis basta acrescentar que descrevem formas específicas de comportamento associadas com dadas tarefas. São padrões de comportamento exigidos de tódas as pessoas que participam de um dado relacionamento funcional. Normas são expectativas gerais de caráter reivindicativo para todos aquêles que desempenham papéis em um sistema. Valôres, finalmente, são justificações e aspiraçōes ideológicas mais gerais. Papéis, normas e valôres compõem as bases da integração do sistema.

Uma vez identificados papéis, normas e valơres como principais componentes de um sistema social, torna-se possível o entendimento da organização em têrmos de trés subsistemas que abrangem todos os que foram mencionados, não se baseando em um critério funcional como no primeiro caso, mas no dos principais componentes. Tais subsistemas seriam: técnico, social e cultural. 0 primeiro compreenderia as tarefas e suas demandas e 
os papéis a ela associados. O segundo, as normas e as relações sociais a ela associadas $\theta$, finalmente, as expectativas sociais mais amplas trazidas pelos insumos humanos que desempenham papéis no subsistema técnico.

Voltando ao critério funcional, também as organizações podem ser classificadas, levando-se primordialmente em conta sua função genotípica, ou seja, a função que exerce como subsistema de sociedade global. Segundo ésse critério, Katz e Kahn 20 distinguem quatro tipos de organizações:

a) Organizaçőes econômicas ou produtivas, relacionadas com o fornecimento de mercadorias $\theta$ serviços, entre as quais estão as emprêsas, inclusive as agrícolas.

b) Organizações de manutençăo, relacionadas com a socialização e o treinamento das pessoas que irão desempenhar papéis em outras organizações e na sociedade global. Entre essas estão as escolas, qualquer que seja o seu nivel, e as igrejas.

c) Organizaçőos adaptativas, relacionadas com a criação de conhecimentos e com o desenvolvimento de novas soluções para problemas. Entre essas estão os laboratórios e organizações de pesquisa, inclusive algumas universidades.

d) Organizaçős politico-administrativas relacionadas com a coordenação e o contrôle de recursos humanos e materiais. $O$ estado, os órgãos públicos em geral, os sindicatos e os grupos de pressão estão nesse grupo.

Por essa tipologia, vemos claramente que, embora uma organização possa ser entendida como um sistema, ela também o poderá ser como um subsistema. $O$ que se define como sistema depende em grande parte do interêsse do analista, porém, a interpretação de uma estrutura social como sistema em relação a outras como supersistema e subsistemas depende de que o sistema tenha um grau de autonomia maior do que os subsistemas e menor do que o supersistema.

20 Katz \& Kahn. The social paychology of organizatlons. Op. cit. cap. 5.

\section{Criticas}

A teoria geral dos sistemas aplicada à teorla das organizações ainda não foi tão criticada quanto outras correntes do pensamento administrativo. Acreditamos que uma das explicações mais relevantes para tal está no fato de que ainda não houve tempo para sua análise mais aprofundada, já que obras mais importantes nessa linha são muito recentes. Além disso, a perspectiva sistêmica parece estar de acôrdo com a preocupação estrutural-funcionalista que vem caracterizando as ciências sociais nos países capitalistas nos últimos tempos, o que pode explicar em parte uma propensão à sua aceitação, ainda que com restrições, pela maior parte dos cientistas sociais dêsses países. Finalmente, a teoria geral dos sistemas na teoria das organizações não trata, a rigor, de temas negligenciados pelos behavioristas e estruturalistas, mas apenas procura desenvolver algumas de suas idéias através de um método. Isto faz com que os autores dessa linha fiquem salvaguardados, já que não se firmou ainda uma tradição de crítica metodológica na teoria das organizaçōes.

De qualquer forma, porém, existem nessa corrente de pensamento alguns pontos críticos que, com o correr dos anos, não poderão deixar de ser explorados pelos espíritos menos conformados, aos quais cabe, em última análise, uma parcela grande da responsabilidade pelo desenvolvimento científico.

Em primeiro lugar, a teoria geral dos sistemas pode ser responsável por uma ilusão científica. Com isto queremos dizer que - elaborado aparato teórico dessa corrente deu aos cientistas sociais a oportunidade de realizarem uma velha aspiração: tornar os objetos de sua ciência suceptiveis de uma análise tão rigorosa quanto a utilizada pelas ciências fís:cas. Ocorre, porém, que os instrumentos utilizados por essas últimas foram desenvolvidos a partir do estudo dos seus objetos e não importados de outras ciências. A primeira linha que vislumbramos para a criti- 


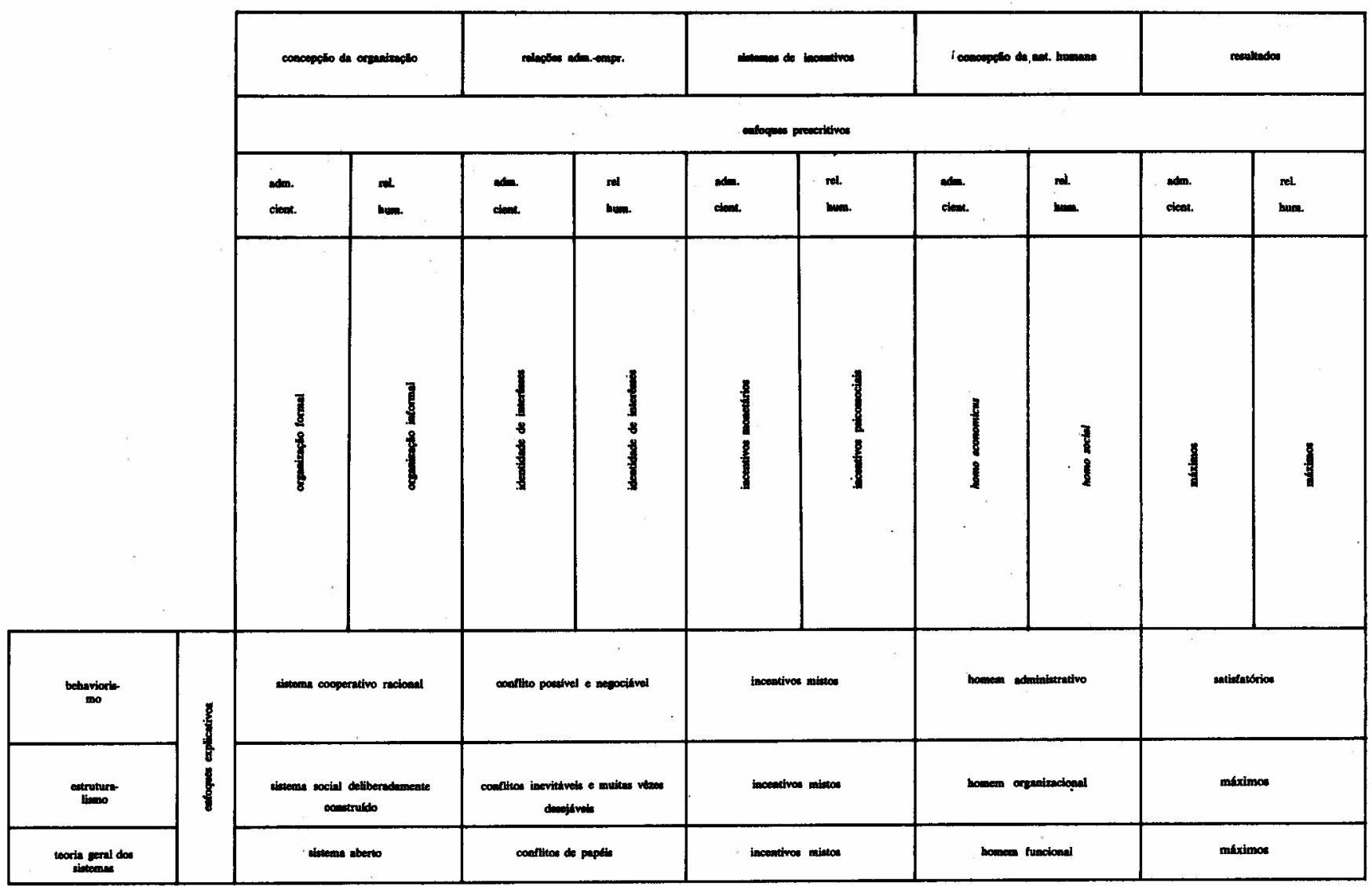

ca da teoria geral dos sistemas na teoria das organizações está no seu biologismo. Nossa pressuposição é a de que ao analisar as organizações utilizando instrumentos importados da biologia e adaptados à natureza social das organizações, o teórico é vítima do que chamamos ilusão cientifica, isto $\dot{\theta}$, passa a acreditar que o objeto de sua análise tende a tornar-se tăo previsivel quanto os sistemas biológicos e que seu campo do conhecimento se presta ao rigor cientifico que caracteriza as ciéncias físicas.

Em segundo lugar, na ênfase dada às relaçōes entre organização $\theta$ ambiente, a maioria dos teóricos de sistemas na análise organizacional parece dar uma importancia excessiva ao papel desempenhado pelo último. A organização depende, para sua sobrevivência, do crescimento e eficiência de sua adaptabilidade ao ambiente, o que quer dizer que a organização mais propensa a sobreviver, crescer e ser eficiente é aquela na qual os papéis, normas $\theta$ valóres estiverem mais de acớrdo com as demandas do ambiente, o que em última análise traduz uma posição idealista que pressupõe a primazia do sistema cultural, com relação aos sistemas social e técnico e que negligencia o papel dinamico das contradiçōes internas das organizações.

E evidente que as causas externas são importantes mesmo no domínio cultural. Ocor- 
re, porém, que sua importância está relacionada com sua ação através das causas internas, que são primárias. Assim, a tentativa de explicar um papel social a partir das normas e essas a partir dos valôres significa uma inversão do processo. Na verdade, os papéis compōem o sistema técnico que determina as normas componentes do sistema social, as quais, por sua vez, determinam os valores, ou o sistema cultural. Influéncias no sentido inverso ocorrem indiscutivelmente, mas constituem um processo secundário.
E curioso que a ênfase no papel do ambiente se desenvolva num país como os Estados Unidos, onde o inverso parece ser muito mais verdadeiro. Com a predominância das grandes organizações, a necessidade do ambiente se adaptar às demandas dos oligopólios parece ser muito mais clara do que a necessidade inversa. E al parece estar um filão precioso para a crítica do caráter ideológico da teoria gerai dos sistemas na teoria das organizaçõos.

A nova CONJUNTURA ECONOMICA permanece tradicional. E ainda objetiva, precisa, imparcial $e$ atualizada. Tudo como antes. Ficou, e claro, mals bonita, moderna, e seu formato o malor. Para facilltar as consultas e tentar, depois, o leitor a deixá-la em cima da mesa,só para enteitar.

Uma publlcaçēo da Fundação Getúlio Vargas. Procure nas bancas ou escreva para a Praia de Botafogo 188, Calxa Postal 21.120, ZC-05, Rio de Janeiro, GB.

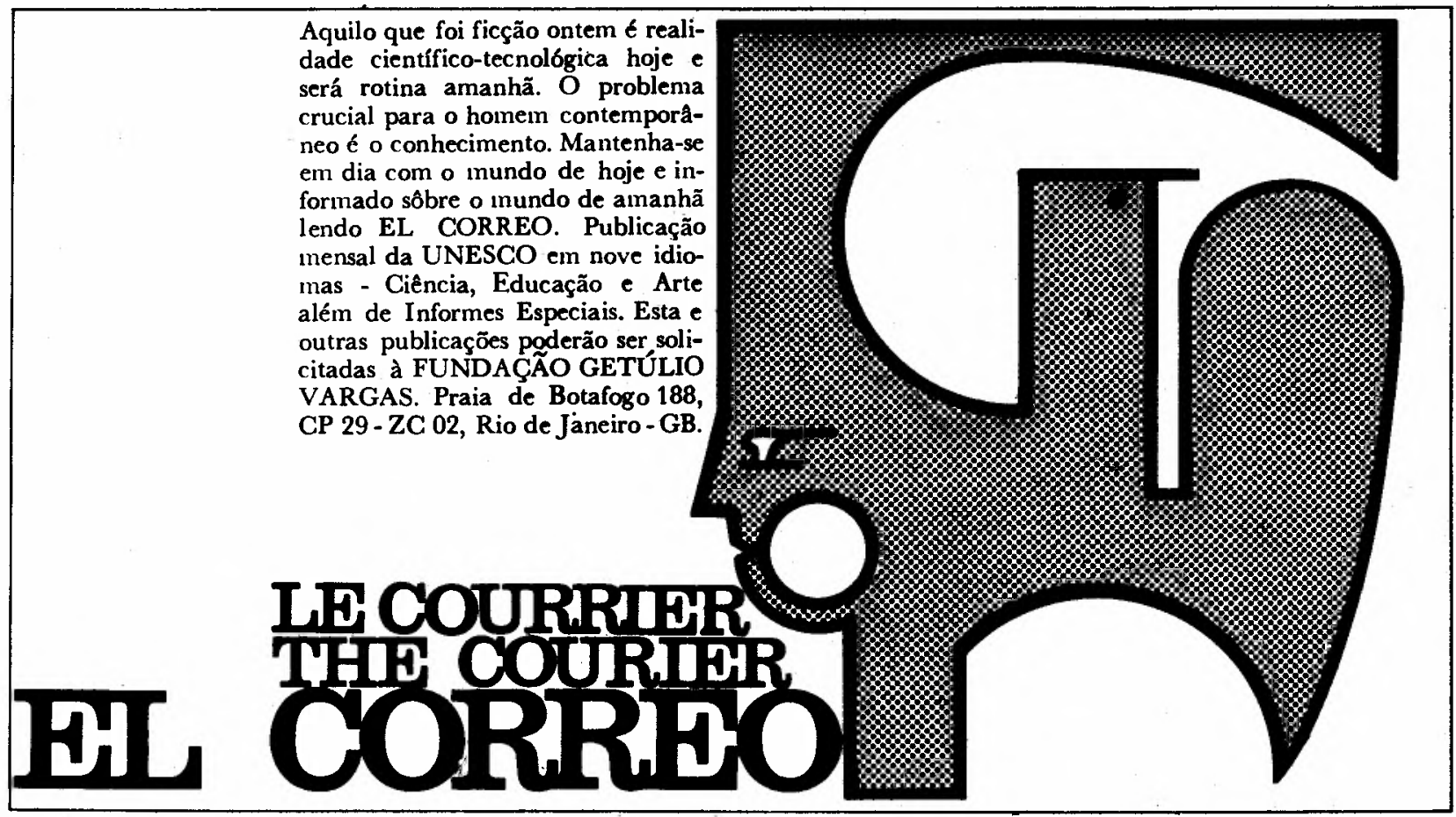

